Brit. Heart F., 1968, 30, 91.

\title{
Long-term Results of DC Reversion of Atrial Fibrillation
}

\author{
M. D. RADFORD AND D. W. EVANS* \\ From the Queen Elizabeth Hospital, Birmingham
}

Early enthusiasm for DC shock as a means of restoring sinus rhythm in patients with atrial fibrillation has been followed by a period of uncertainty as to the place of such treatment in the long-term management of this arrhythmia. Whatever the haemodynamic advantages of co-ordinate and appropriately-phased atrial contraction (Braunwald, 1964; Burchell, 1964), restoration of sinus rhythm seems therapeutically justifiable only when it is likely to persist for a worth-while period; otherwise any such advantages will be ephemeral and the risk of embolism is unlikely to be favourably influenced. We, therefore, attempted to clarify the position by follow-up of patients treated over two years ago in order to determine the rates of persistence of normal rhythm at one or two years after reversion in different aetiological groups.

\section{SUBJECTS AND METHODS}

Between November 1963 and February 1965, 156 patients with atrial fibrillation were treated by DC shock through the closed chest. A Lown defibrillator was used and the technique has been reported elsewhere (Evans and Robson, 1965). The initial shock was of 100 joules energy, lower energies perhaps carrying a higher risk of serious induced arrhythmia (Nachlas et al., 1966). Where reversion was not achieved, up to 3 more shocks were given (maximum energy 400 joules) before the attempt was abandoned. Sinus rhythm was thus restored in $64(73 \%)$ of 88 patients with rheumatic heart disease, $19(79 \%)$ of 24 with "lone" atrial fibrillation, $17(85 \%)$ of 20 with treated thyrotoxicosis, 14 $(82 \%)$ of 17 with hypertensive and/or coronary heart disease, all 4 with congenital heart disease, and 2 of 3 with surgically-treated constrictive pericarditis. Of these 120 patients, 119 were followed for two years after

Received May 22, 1967.

* Present address: The Cardiac Unit, Papworth Hospital, Nr. Cambridge. reversion, or to earlier death or (first) relapse to atrial fibrillation. They form the basis of this study and their cardiac diagnoses and age and sex distribution are shown in Table I. Those with hypertension and/or coronary artery disease have been grouped together because of the frequent coexistence of these conditions and the difficulty in deciding which is dominant in the present context. The patient lost to follow-up was a 60 -yearold man with "lone" atrial fibrillation of 2 months' duration who regained sinus rhythm after 2 shocks.

TABLE I

FOLLOW-UP GROUP OF 119 PATIENTS WITH ATRIAL FIBRILLATION REVERTED TO SINUS RHYTHM

\begin{tabular}{|c|c|c|c|c|}
\hline \multirow{2}{*}{ Aetiology } & \multirow{2}{*}{ No. } & \multicolumn{2}{|r|}{ Sex } & \multirow{2}{*}{$\begin{array}{c}\text { Age (yr.) } \\
\text { (range and } \\
\text { mean) }\end{array}$} \\
\hline & & Male & Female & \\
\hline \multirow{3}{*}{$\begin{array}{l}\text { Rheumatic } \\
\text { "Lone" } \\
\text { Thyrotoxic } \\
\text { Hypertensive and/or } \\
\text { coronary } \\
\text { Congenital } \\
\text { Constrictive } \\
\text { pericarditis }\end{array}$} & $\begin{array}{l}64 \\
18 \\
17\end{array}$ & $\begin{array}{r}23 \\
14 \\
6\end{array}$ & $\begin{array}{r}41 \\
4 \\
11\end{array}$ & $\begin{array}{l}26-69(47 \cdot 5) \\
32-73(56 \cdot 7) \\
39-68(58 \cdot 7)\end{array}$ \\
\hline & $\begin{array}{r}14 \\
4 \\
?\end{array}$ & $\begin{array}{l}9 \\
3\end{array}$ & $\begin{array}{l}5 \\
1\end{array}$ & $\begin{array}{l}38-84(59 \cdot 3) \\
37-58(46 \cdot 3)\end{array}$ \\
\hline & 2 & 2 & $\mathbf{0}$ & $38-49(43 \cdot 5)$ \\
\hline
\end{tabular}

Quinidine prophylaxis ( 0.4 g.t.d.s.), which was started 3 hours before the shock was given, was administered to 34 of the 119 patients, a test dose of $0.2 \mathrm{~g}$. having been given uneventfully the day before. Quinidine was withdrawn from every patient after one died suddenly at home a month after her second reversion, another developed ventricular fibrillation and died three days after reversion, and a third suffered a series of attacks of ventricular tachycardia (with syncope and convulsions) which ceased when quinidine was withdrawn (Brenner, Davison, and Evans, 1964). No patient therefore continued quinidine for more than 5 months and most of the 34 received it for a much shorter time. Diagnostic and other data for the group of patients given quinidine and for the remainder given no prophylactic are shown for comparison in Table II. 
TABLE II

GROUPS GIVEN QUINIDINE OR NO PROPHYLACTIC

\begin{tabular}{l|c|c}
\hline & $\begin{array}{c}\text { Prophylactic } \\
\text { quinidine }\end{array}$ & $\begin{array}{c}\text { No } \\
\text { prophylaxis }\end{array}$ \\
\hline Totals & 34 & 85 \\
\hline Aetiology & 26 & 38 \\
Rheumatic & 3 & 15 \\
"Lone" & 3 & 14 \\
Thyrotoxic & 1 & 13 \\
Hypertensive and/or coronary & 0 & 4 \\
Congenital & 1 & 1 \\
Constrictive pericarditis & 13 & 44 \\
Atrial fibrillation before reversion & 16 & 30 \\
<6 mth. & 5 & 11 \\
6 mth.-5 yr. & 16 & 19 \\
>5 yr. & 28 & 69 \\
Congestive failure at or before reversion & 6 & 16 \\
Shocks required & 25 & 57 \\
1 or 2 & & \\
3 or 4 & & \\
Cardiomegaly & & \\
\end{tabular}

Digitalis therapy, in dosage up to $0.5 \mathrm{mg}$. digoxin or equivalent daily, was continued after reversion in 19 patients. These had all been digitalized for some reason other than atrial fibrillation itself or had tight mitral stenosis with its attendant risk of inadequate left ventricular filling if the arrhythmia should have recurred in the absence of adequate $\mathrm{A}-\mathrm{V}$ block. In the other patients digitalis medication was discontinued before reversion, usually 24-36 hours before in the case of digoxin.

Of the 120 patients, 26 were already receiving longterm anticoagulant therapy on account of past systemic embolism at the time of reversion. The others were not given anticoagulants (though our practice in this respect has changed subsequently) and no instance of early post-reversion embolism was recorded in this series.

One patient, a 64-year-old woman with treated thyrotoxicosis and hypertension, developed ventricular fibrillation and died while sitting in a water-closet about 8 hours after reversion. She was not receiving quinidine, and digoxin therapy (dose uncertain) had been discontinued when she was nauseated on admission to hospital 36 hours before the 2 reverting shocks were given. She exhibited multifocal ventricular extrasystoles both before and immediately after the shocks and may have been still excessively under the influence of digitalis.

An attempt was made to detect factors influencing the duration of sinus rhythm in the 119 patients followed to completion. This involved analysis of data recorded on cards punched at the time of reversion. The available information included age, sex, aetiology of heart disease, and nature of any valve lesion present, presence or history of congestive failure, presence or absence of cardiomegaly (increased cardiothoracic ratio), history of cardiac or thyroid operation, whether on digitalis at the time or given an anti-arrhythmic drug prophylactically, number of shocks required to restore sinus rhythm, and duration of antecedent atrial fibrillation. It was a deficiency of the system used that those with atrial fibrillation of 6 months' to 5 years' duration were grouped together, and more precise figures for duration of antecedent arrhythmia could not subsequently be obtained in most cases.

Of the 101 patients who relapsed to atrial fibrillation within the follow-up period, 30 were again given DC shocks with the object of restoring sinus rhythm and this was again attained in $27(90 \%)$. All these were similarly followed to second relapse. Nine patients underwent third defibrillation attempts (all successful) and were again followed to relapse. One patient insisted upon, and received, a fourth series of shocks which again restored sinus rhythm but he did not maintain it for even 24 hours.

\section{RESULTS}

With the exception of the 2 early post-reversion deaths noted above, none of the 119 patients died before first relapse to atrial fibrillation or completion of the 2-year follow-up period.

The numbers of patients in each aetiological group who maintained sinus rhythm for 3 months, 1 year, and 2 years, respectively, after initial reversion are shown in Table III. The Figure shows the percentage persistence of sinus rhythm against time after reversion in the rheumatic, "lone", and thyrotoxic groups. It will be seen that 35 per cent of patients whose atrial fibrillation was considered to be due to (treated) thyrotoxicosis maintained sinus rhythm for 2 years after reversion, whereas only 9 per cent of those with chronic rheumatic heart disease did so; those adjudged, at the time of reversion, to have "lone" atrial fibrillation occupied an intermediate position $(22 \%$ persistence at 2 years). None of those with hypertensive and/or ischaemic heart disease maintained sinus rhythm for 2 years though one did so for 1 year.

Age, sex, and presence or absence of cardiac enlargement exerted no apparent influence on persistence of sinus rhythm after first reversion in the thyrotoxic or rheumatic groups. No important factor emerged from analysis of the "lone" group, some of whom subsequently proved to have some form of chronic myocardial or endocardial disorder. The apparent effects of other factors are detailed below.

Thyrotoxic Atrial Fibrillation Group. The number of shocks required, and past or present congestive failure, appeared to be without influence upon the long-term persistence of sinus rhythm. Neither of the patients with antecedent atrial fibrillation of over 5 years' duration maintained sinus rhythm for 1 year after reversion. Inadequate thyroid suppression (by medical means) was considered responsible for relapse to atrial fibrillation in one patient whose arrhythmia recurred within 
24 hours. Recurrence of thyrotoxicosis was probably responsible for later return of the arrhythmia in at least one other patient. Another possible aetiological factor (systemic hypertension) was present in 4 of those whose atrial fibrillation recurred within a year.

Rheumatic Heart Disease Group. None of those with a history of congestive failure or who required more than two shocks (the second of 200 joules) maintained sinus rhythm for 1 year after reversion. None of the 12 patients with more than 5 years' atrial fibrillation were still in sinus rhythm at 1 year. The type or varieties of valve lesion present appeared to exert no influence in this respect.

Of those 7 patients in this series who first developed atrial fibrillation at, or within 6 weeks of, mitral valvotomy, all regained sinus rhythm after 1 shock, and 2 maintained normal rhythm subsequently for 2 years. One, who was given quinidine prophylaxis, died in ventricular fibrillation 3 days after reversion, as mentioned above.

Quinidine Prophylaxis. Figures for persistence of sinus rhythm at 1 month after first reversion in those given quinidine and the remainder given no prophylactic are shown in Table IV. Also shown are the figures for 3 months' post-reversion, though by this time most of the "quinidine group" had been required to discontinue the drug following the demise of 2 of their number. Even so, the "quinidine group" appears to have fared somewhat better in respect of non-relapse to atrial fibrillation by this time, notwithstanding the fact that their
TABLE III

PERSISTENCE OF SINUS RHYTHM AFTER FIRST REVERSION BY AETIOLOGICAL GROUP

\begin{tabular}{l|c|c|c|c|}
\hline & $\begin{array}{c}\text { Reverted } \\
\text { and } \\
\text { followed }\end{array}$ & \multicolumn{2}{|c|}{ Still in sinus rhythm at* } \\
\cline { 4 - 6 } & 64 & $29(45)$ & $7(11)$ & $6(9)$ \\
\hline $\begin{array}{l}\text { Rheumatic } \\
\text { "Lone" }\end{array}$ & 18 & $10(56)$ & $6(33)$ & $4(22)$ \\
Thyrotoxic & 17 & $10(59)$ & $6(35)$ & $6(35)$ \\
Hypertensive and/or & 14 & 5 & 1 & 0 \\
coronary & 4 & 2 & 1 & 0 \\
Congenital & 2 & 0 & 0 & 0 \\
Constrictive pericarditis & 119 & $56(47)$ & $21(18)$ & $16(13)$ \\
\hline Totals & 11 & & \\
\hline
\end{tabular}

* Percentages are given in parentheses.

TABLE IV

SINUS RHYTHM PERSISTENCE IN QUINIDINE AND NO-PROPHYLACTIC GROUPS

\begin{tabular}{l|c|c}
\hline & $\begin{array}{c}\text { Prophylactic } \\
\text { quinidine }\end{array}$ & $\begin{array}{c}\text { No } \\
\text { prophylaxis }\end{array}$ \\
\hline Totals & 34 & 85 \\
$\begin{array}{l}\text { Still in sinus rhythm at } \\
\quad 1 \text { mth. }\end{array}$ & $22(65)$ & $49(58)$ \\
3 mth. & $20(59)$ & $36(42)$ \\
\hline
\end{tabular}

* Percentages are given in parentheses.

members had a higher incidence of failure history and a lower incidence of thyrotoxic and "lone" fibrillation. However, they also had a much lower incidence of the apparently unfavourable hypertensive-coronary aetiology.

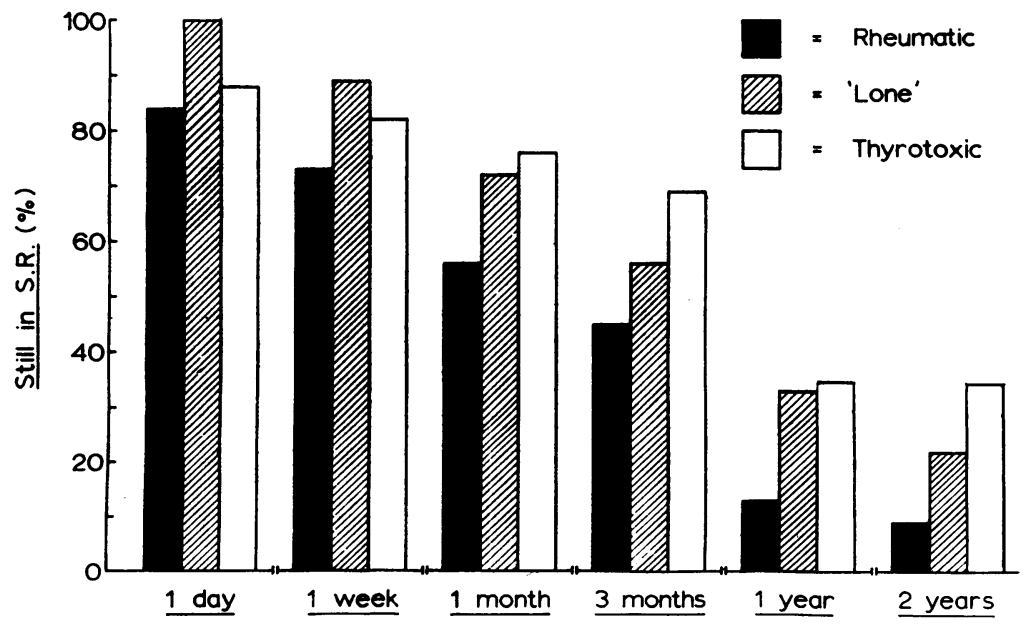

FIG.-Percentages of patients in rheumatic, "lone", and thyrotoxic groups still in sinus rhythm at 1 day to 2 years after reversion. 
Continued Digitalis Medication. The constitution of this group was similar to the whole. Of the 19, $3(16 \%)$ were still in sinus rhythm 1 year after reversion and $2(11 \%)$ at 2 years.

Second and Third Reversions. Only 1 of the 27 patients reverted for a second time after first relapse maintained sinus rhythm subsequently for a year, and he again relapsed at 13 months. None of the 9 patients who reverted a third time thereafter maintained normal rhythm for more than 3 months.

\section{Discussion}

Although restoration of normal sinus rhythm may seem desirable on theoretical grounds, it will be practically useful only if persistent and accompanied by atrial contraction. The latter does not necessarily follow (Braunwald, 1964) and may perhaps be disadvantageous in some circumstances (McDonald, Resnekov, and O'Brien, 1964). In patients with rheumatic heart disease the risk of embolism, while greater in those with atrial fibrillation (Szekely, 1964), is presumably decreased only so long as sinus rhythm persists after reversion; subsequent relapse to atrial fibrillation might carry a renewed high risk of embolism for a while.

The chances of long-term persistence of normal rhythm after reversion therefore merit critical study. Halmos (1966a) found 42 per cent of his patients with atrial fibrillation still in sinus rhythm at 9 months after the reverting shock, whereas Killip and Yormak (1965) found only 27 per cent of their patients in sinus rhythm at one year. Our over-all one-year figure $(18 \%)$ is not encouraging and our two-year figure (13\%) still less so. Specific subgroups may, however, do better, as discussed below.

In view of the doubtful long-term prospects, and the fact that chronic atrial fibrillation is often so well tolerated (Chevalier, 1966), the risks of reversion may assume greater significance. Most reported series mention embolic episodes sufficiently close in time to be reasonably attributable to the resumption of sinus rhythm. The fact that no immediate post-reversion embolism was recognized in this series may, if not due entirely to chance, reflect hidden selection (i.e. non-referral when the clinician in charge felt the risk to be high) or be attributable to the long-term anticoagulant therapy already being given to those 26 patients with a history of systemic embolism. Two patients subsequently reverted by this means, i.e. not in this series, have suffered cerebral embolism within 24 hours; neither was given anticoagulants prophylactically. Both had atrial fibrillation of approximately 6 months' duration, in one case due to rheumatic heart disease and in the other associated with coronary insufficiency. It has since been our routine practice to give anticoagulants for 2 weeks beforehand and for a few days after the reversion attempt. The fatality due to ventricular fibrillation 8 hours after reversion may have been related to the electrical discharge, perhaps aided and abetted by persistent digitalis effect (Castellanos, Lemberg, and Fonseca, 1965; Gilbert and Cuddy, 1965). However, none of the 19 patients whose digitalis medication was deliberately continued showed evidence of serious arrhythmia after reversion.

There were no other catastrophes within 24 hours of the shock treatment, but a 25-year-old woman developed ventricular fibrillation and died 3 days after reversion. Her death, and another which occurred suddenly one month after a second reversion, were attributed to quinidine given prophylactically. Because of these deaths, and a series of paroxysms of ventricular tachycardia in another patient, the practice of giving quinidine was discontinued. Similar serious ventricular arrhythmias and sudden deaths can be found in many reports of patients given quinidine (e.g. Baker, Robinson, and Trounce, 1956; Binder and Rosove, 1952; Bloom, 1963; Halmos, 1966a; Killip and Yormak, 1965; Korsgren et al., 1965; Paulk and Hurst, 1965; Rubeiz, El-Haji, and Touma, 1965; Selzer and Wray, 1964; Selzer et al., 1966; Sokolow and Ball, 1956; Thomson, 1956) and in the records of this and other hospitals. We therefore agree with Oram and Davies (1964) that this drug is too dangerous for routine use. This conclusion, though inevitable, is regrettable in so far as quinidine is probably an effective prophylactic against recurrence of chronic atrial fibrillation (Hurst et al., 1964; Korsgren et al., 1965; Lown, 1964), though others may deny it (Chevalier, 1966; Halmos, 1966a).

Factors emerging from this study as important determinants of the probability of persistence of normal rhythm include aetiology, duration of the atrial fibrillation at the time of reversion, and in those with rheumatic heart disease, the number of discharges required to restore sinus rhythm, presence or history of congestive failure, and, possibly, onset of atrial fibrillation shortly after mitral valvotomy. At the present time we conclude that, with proper precautions, the attempt to restore sinus rhythm is justifiable in the following circumstances.

(1) Where atrial fibrillation is considered due to thyrotoxicosis, provided that the patient has been rendered euthyroid by medical or surgical means before the attempt is made. Such prior treatment 
often, of course, results in "spontaneous" reversion and renders shock treatment unnecessary.

(2) Where atrial fibrillation is adjudged "lone" or due to remediable cause, especially if the arrhythmia is of short duration or causing symptoms.

(3) In subjects with chronic rheumatic heart disease whose atrial fibrillation first develops shortly after mitral valvotomy or, perhaps, other cardiac surgery. These patients also have a tendency to reacquire sinus rhythm spontaneously (Bloom, 1963; Halmos, 1966b), and the electrical reversion attempt should ordinarily, therefore, be delayed for 2 to 4 weeks.

It is doubtful whether attempts to restore sinus rhythm in other patients with rheumatic heart disease are worth while or desirable. Those with over 5 years' atrial fibrillation, or with a history of congestive failure, should certainly not be considered for reversion in our view. If it is decided to make the attempt in others no more than two shocks should be given (100 joules and 200 joules), for if higher energies are required to achieve reversion the prognosis for persistence of sinus rhythm is poor.

We have too little experience of atrial fibrillation of other aetiology on which to base current policy decisions. Like Selzer et al. (1966), however, we have been disappointed with the long-term results in those with hypertensive and/or coronary artery disease.

Second and third reversions in this series of patients have proved futile in the long run but such attempts seem justifiable where relapse to atrial fibrillation is considered due to a remediable cause such as recurrent thyrotoxicosis or intake of alcohol.

\section{SUMMARY}

Follow-up studies were made on 119 patients in whom sinus rhythm had been restored electrically after atrial fibrillation had been present for various periods. The follow-up lasted for 2 years from the date of reversion or to prior relapse or death.

Of those whose atrial fibrillation was initially due to thyrotoxicosis (treated before reversion), 35 per cent were still in sinus rhythm at 1 year and the figure was the same at 2 years. The corresponding figures for the group considered to have "lone" atrial fibrillation were 33 per cent and 22 per cent.

Only 13 per cent of those with rheumatic heart disease maintained sinus rhythm for 1 year and 9 per cent for 2 years after reversion. It is suggested that attempts to restore sinus rhythm in these patients should be restricted to those whose arrhythmia develops for the first time shortly after cardiac surgery.
These conclusions may require drastic revision if a safe and effective anti-arrhythmic drug becomes available for prophylaxis. Quinidine is too dangerous for use in this context.

We are grateful to the late Dr. O. Brenner and to Drs. P. H. Davison and J. G. Domenet for encouragement and advice. Our thanks are due also to the many physicians and surgeons of this and other hospitals who referred their patients for treatment and allowed us to follow them up.

Miss J. Henderson and her colleagues in the Department of Electrocardiography gave invaluable assistance throughout. Mr. T. F. Dee kindly prepared the Figure.

\section{REFERENCES}

Baker, C. G., Robinson, B. H. B., and Trounce, J. R. (1956). Ventricular tachycardia and fibrillation following quinidine. Guy's Hosp. Rep., 105, 433.

Binder, M. J., and Rosove, L. (1952). Paroxysmal ventricular tachycardia and fibrillation due to quinidine. Amer. f. Med., 12, 491 .

Bloom, V. R. (1963). The prognosis of atrial fibrillation following mitral valvotomy. Brit. Heart f., 25, 595.

Braunwald, E. (1964). Hemodynamic significance of atrial systole. Amer. F. Med., 37, 665.

Brenner, O., Davison, P. H., and Evans, D. W. (1964). Toxicity of quinidine. Lancet, $2,1184$.

Burchell, H. B. (1964). A clinical appraisal of atrial transport function. Lancet, 1, 775.

Castellanos, A., Jr., Lemberg, L., and Fonseca, E. J. (1965). Significance of ventricular and pseudoventricular arrhythmias appearing after D.C. countershock. Amer. Heart F., 70, 583.

Chevalier, H. (1966). A plea for atrial fibrillation. Amer. Heart f., 72, 423.

Evans, D. W., and Robson, J. E. S. (1965). Atrial de-fibrillation by D.C. shock. Midl. med. Rev., 4, 91 .

Gilbert, R., and Cuddy, R. P. (1965). Digitalis intoxication following conversion to sinus rhythm. Circulation, $32,58$.

Halmos, P. B. (1966a). Direct current conversion of atrial fibrillation. Brit. Heart F., 28, 302.

- (1966b). The prognosis of atrial fibrillation after mitral valvotomy. Amer. Heart f., 72, 30.

Hurst, J. W., Paulk, E. A., Jr., Proctor, H. D., and Schlant, R. C. (1964). Management of patients with atrial fibrillation. Amer. F. Med., 37, 728.

Killip, T., and Yormak, S. (1965). Short- and long-term results from direct-current conversion for atrial fibrillation and flutter. Circulation, 31 and 32, Suppl. II, 125.

Korsgren, M., Leskinen, E., Peterhoff, V., Bradley, E., and Varnauskas, E. (1965). Conversion of atrial arrhythmias with DC shock. Primary results and a follow-up investigation. Acta med. scand., Suppl. 431.

Lown, B. (1964). "Cardioversion" of arrhythmias (II). Mod. Conc. cardiovasc. Dis., 33, 869.

McDonald, L., Resnekov, L., and O'Brien, K. (1964). Direct-current shock in treatment of druy-resistant cardiac arrhythmias. Brit. med. F., 1, 1468.

Nachlas, M. M., Bix, H. H., Mower, M. M., and Siedband, M. P. (1966). Observations on defibrillators, defibrillation, and synchronized countershock. Progr.cardiovasc. Dis., 9, 64. 
Oram, S., and Davies, J. P. H. (1964). Further experience of electrical conversion of atrial fibrillation to sinus rhythm: analysis of 100 patients. Lancet, 1, 1294.

Paulk, E. A., and Hurst, J. W. (1965). Clinical problems of cardioversion. Amer. Heart f., 70, 248.

Rubeiz, G. A., El-Haji, M., and Touma, A. (1965). Successful use of external electrical cardioversion in the treatment of ventricular fibrillation caused by quinidine. Amer. F. Cardiol., 16, 118.

Selzer, A., Kelly, J. J., Jr., Johnson, R. B., and Kerth, W. J. (1966). Immediate and long-term results of electrical conversion of arrhythmias. Progr. cardiovasc. Dis., 9, 90.
- and Wray, H. W. (1964). Quinidine syncope. Paroxysmal ventricular fibrillation occurring during treatment of chronic atrial arrhythmias. Circulation, 30, 17.

Sokolow, M., and Ball, R. E. (1956). Factors influencing conversion of chronic atrial fibrillation with special reference to serum quinidine concentration. Circulation, $14,568$.

Szekely, P. (1964). Systemic embolism and anticoagulant prophylaxis in rheumatic heart disease. Brit. med. $\mathcal{f}$., $1,1209$.

Thomson, G. W. (1956). Quinidine as a cause of sudden death. Circulation, 14, 757 . 